\title{
Identification of miR-30b as an oncogene in renal cell carcinoma
}

\author{
LU JIN ${ }^{1-3^{*}}$, YIFAN LI ${ }^{1-3^{*}}$, TAO HE ${ }^{1,3,4}$, JIA HU $^{1,3,4}$, JIAJU LIU $^{1,3,5}$, MINGWEI CHEN $^{2,3}$, MIN SHI $^{3}$, \\ ZHIMAO JIANG $^{3}$, SHANGQI YANG ${ }^{1,3}$, XIANGMING MAO ${ }^{1,3}$, YAOTING GUI ${ }^{3}$ and YONGQING LAI ${ }^{1,3}$
}

\begin{abstract}
${ }^{1}$ Department of Urology, Peking University Shenzhen Hospital, Shenzhen, Guangdong 518036; ${ }^{2}$ Department of Urology, Anhui Medical University, Hefei, Anhui 230032; ${ }^{3}$ The Guangdong and Shenzhen Key Laboratory of Male Reproductive Medicine and Genetics, Peking University Shenzhen Hospital, Institute of Urology of Shenzhen PKU-HKUST Medical Center, Shenzhen, Guangdong 518036; ${ }^{4}$ Department of Urology, Guangzhou Medical University, Guangzhou, Guangdong 511436; ${ }^{5}$ Department of Urology, Shantou University Medical College, Shantou, Guangdong 515041, P.R. China
\end{abstract}

Received November 24, 2015; Accepted November 30, 2016

DOI: $10.3892 / \mathrm{mmr} .2017 .6197$

\begin{abstract}
RNAs (miRs) have been investigated as a novel class of regulators of cellular processes, including proliferation, apoptosis and metabolism. In particular, miR-30b has been demonstrated to be deregulated in certain types of cancer, including lung, colorectal and gastric cancer. Previous studies of miR-30b in renal clear cell carcinoma demonstrated that the expression level of miR-30b was associated with distant metastasis. However, the function of miR-30b in renal cell carcinoma (RCC) remained to be elucidated. In the present study, the expression of miR-30b in 31 paired RCC tissues from four cell lines (786-O, 769-P, ACHN and 293T) was detected by reverse transcription-quantitative polymerase chain reaction. In addition, the effect of miR-30b on cell proliferation in RCC cells was also determined using MTT and Cell Counting Kit- 8 assay analyses. Furthermore, the function of miR-30b in cell migration and invasion was determined by wound scratch and Transwell assays. Flow cytometry was also performed to quantify the effect of miR-30b on cell apoptosis. The results of the current study indicated that miR-30b was upregulated in RCC tissues from affected cell lines when compared with adjacent normal tissues and a normal kidney cell line, which is different to the downregulation of miR-30b as observed in
\end{abstract}

Correspondence to: Professor Yongqing Lai, Department of Urology, Peking University Shenzhen Hospital, 1120 Lianhua Road, Shenzhen, Guangdong 518036, P.R. China

E-mail: yqlord@163.com

Professor Yaoting Gui, The Guangdong and Shenzhen Key Laboratory of Male Reproductive Medicine and Genetics, Peking University Shenzhen Hospital, Institute of Urology of Shenzhen PKU-HKUST Medical Center, 1120 Lianhua Road, Shenzhen, Guangdong 518036, P.R. China

E-mail: gyt@pkuszh.com

${ }^{*}$ Contributed equally

Key words: microRNA, miR-30b, renal cell carcinoma, oncogene other types of cancer. miR-30b is associated with RCC cell proliferation, invasion, migration and apoptosis, which indicated that miR-30b acts as an oncogene in RCC. To the best of our knowledge, the present study is the first to demonstrate the upregulation of miR-30b in RCC tissues and describe miR-30b as an oncogene in RCC in the regulation of cell proliferation, migration, invasion and apoptosis. Further studies will define the target gene of miR-30b in RCC and investigate the potential role of miR-30b as a biomarker for RCC.

\section{Introduction}

Renal cell carcinoma (RCC) is the most common type of kidney cancer, accounting for $\sim 5 \%$ of malignant cancers in males, and $3 \%$ in females, according to a survey in 2013 in the USA $(1,2)$. The estimated statistics in the study demonstrated that the incidence and the mortality rate of RCC were among the ten leading types of cancer, with $>65150$ new cases accounting for $>13680$ mortalities recorded (2). During the early stage of RCC, patients have no characteristic clinical feature and $30 \%$ of the RCC patients have an evidence of metastasis at diagnosis (3). Common metastatic sites of RCC are the lung, bone, lymph node, liver, adrenal glands and brain (4,5). Surgical treatment followed by radiotherapy and chemotherapy is the predominant therapeutic strategy for RCC. However, high recurrence rates of $20-40 \%$ patients are observed during the treatment (6). The 5-year survival rate of RCC is estimated to be $\sim 55 \%$ and $<10 \%$ in patients with metastatic RCC (7). Thus, diagnosis of RCC at an early stage may improve the prognosis of RCC patients, and it is key to identify a novel biomarker to diagnose or offer a targeted therapy for RCC.

Noncoding RNA (ncRNA) is considered to serve a critical role in the regulation of multiple cellular processes. microRNAs (miR) are a class of small ncRNAs at a length of 20 nucleotides $(8,9)$. In the majority of types of cancer, miRNAs may modulate key processes by binding to mRNA to induce translational repression or degradation $(10,11)$. miRs may act as oncogenes or tumor suppressor genes, according to the mRNA that they target (12). A number of studies have focused on aberrantly expressed miRs and function in different diseases, particularly in tumors. miR-30b, a member 
of the miR-30b family, has been identified as abnormally expressed in different tumors, including those found in gastric cancer, colorectal cancer and non-small cell lung cancer (NSCLC) (13-15). A previous study demonstrated using microarray that miR-30b was downregulated in RCC (16), whilst another indicated miR-30b was upregulated in RCC tissues and serum (17). The expression of miR-30b has not previously been verified by reverse transcription-quantitative polymerase chain reaction (RT-qPCR) in RCC tissues. In the present study, the expression of miR-30b was detected in RCC tissues and cell lines, and, the function of miR-30b in RCC cell lines (ACHN and 786-O) was investigated.

\section{Materials and methods}

Sample collection. A total of 31 paired tissues were collected from Peking University Shenzhen Hospital (Shenzhen, China) between December 2012 and December 2014. There were 19 males and 12 female patients (age range, 25-75). Written informed consent was obtained from all patients. Collection and usage of the samples were reviewed and approved by the Ethics Committees of Peking University Shenzhen Hospital. The tissues were immersed in RNAlater (Qiagen $\mathrm{GmbH}$, Hilden, Germany) for $30 \mathrm{~min}$ following dissection, prior to storing the tissues at $-80^{\circ} \mathrm{C}$ until further use. A pair of tissue constitutes an affected RCC tissue and adjacent normal tissue, which is $2 \mathrm{~cm}$ away from visible RCC lesions. The tissues collected were reviewed and classified by hematoxylin and eosin staining. The clinical and pathological characteristics of the patients are presented in Table I.

Cell culture. The 293T human embryo kidney cell line was obtained from the Type Culture Collection of the Chinese Academy of Medical Sciences (Shanghai, China) and three RCC cell lines, 786-O, ACHN and 769-P were purchased from the American Type Culture Collection (Manassas, VA, USA) for use in the present study.

Cells were cultured in Dulbecco's modified Eagle's medium (Gibco; Thermo Fisher Scientific, Inc., Waltham, MA, USA) supplemented with $10 \%$ fetal bovine serum (Gibco; Thermo, Fisher Scientific, Inc.), $1 \%$ antibiotics $(100 \mu \mathrm{l} / \mathrm{ml}$ penicillin and $100 \mathrm{mg} / \mathrm{ml}$ streptomycin sulfates) and $1 \%$ glutamine in the humidified incubator containing $5 \% \mathrm{CO}_{2}$ at $37^{\circ} \mathrm{C}$.

RNA extraction, cDNA synthesis and qPCR. Total RNA was extracted from the tissues and cells by TRIzol reagent (Invitrogen; Thermo Fisher Scientific, Inc.) and purified with the RNeasy Maxi kit (Qiagen $\mathrm{GmbH}$ ) according to the manufacturer's protocols. The concentration of RNA was measured using a NanoDrop 2000/2000c (Thermo Fisher Scientific, Inc.). A total of $1 \mu \mathrm{g}$ total RNA of each sample was used for reverse transcription by miScript Reverse Transcription kit (Qiagen) according to the manufacturer's instructions to obtain cDNA. RT-qPCR was performed to detect the expression level of miR-30b using the miScript SYBR $®$ green PCR Kit (Qiagen $\mathrm{GmbH}$ ) on the Roche Lightcycler 480 Real-Time PCR system (Roche Diagnostics, Basel, Switzerland) according to the manufacturer's protocols. The conditions of RT-qPCR were: $95^{\circ} \mathrm{C}$ for $1 \mathrm{~min}$, then $95^{\circ} \mathrm{C}$ for $10 \mathrm{sec}, 55^{\circ} \mathrm{C}$ for $30 \mathrm{sec}, 70^{\circ} \mathrm{C}$ for $30 \mathrm{sec}$, for 40 cycles. U6 served as the internal control.
The sequences of the primers are presented in Table II. The universal primer was provided by the miScript SYBR ${ }^{\circledR}$ green PCR kit, which was used as the reverse primer for miR-30b. The expression levels of miR-30b were analyzed using the $2^{-\Delta \Delta \mathrm{Cq}}$ method (18).

Cell transfection. For upregulation or downregulation of miR-30b, synthesized miR-30b mimic or inhibitor (Shanghai GenePharma Co., Ltd., Shanghai, China) was transfected into cells using Lipofectamine 2000 (Invitrogen; Thermo Fisher Scientific, Inc.), which was mixed in Opti-MEM ${ }^{\circledR} \mathrm{I}$ Reduced Serum medium (Gibco; Thermo Fisher Scientific, Inc.) following plating for $24 \mathrm{~h}$. Cells were transfected for $4 \mathrm{~h}$ at $37^{\circ} \mathrm{C}$. Cells transfected with the miR-30b mimic negative control (NC) or inhibitor $\mathrm{NC}$ formed the control group. RT-qPCR was then performed, as before, to verify the changes of miR-30b expression following transfection for $24 \mathrm{~h}$. The sequences are presented in Table II.

Wound healing assay. The wound healing assay was performed to assess the cell migration ability of 786-O and ACHN cells in vitro. Approximately $3 \times 10^{5}$ cells were seeded in each well of the 12-well plate, and the cells were transfected with 40 pmol of miR-30b mimics, inhibitors, negative control or inhibitor negative control after $24 \mathrm{~h}$. A vertical horizontal line was scratched with a sterile $200 \mu \mathrm{l}$ pipette tip $6 \mathrm{~h}$ after transfection. The cells were rinsed with phosphate-buffered saline (PBS) to remove the floating cells. A digital camera system was used to acquire the images of the scratches at 0 and $24 \mathrm{~h}$ following the scratch. The experiments were performed in triplicate and repeated at least three times.

Transwell assay. A Transwell assay was performed to assess the cell migration and invasion ability of 786-O and ACHN cells in vitro. Transwell chamber inserts (BD Biosciences, Franklin Lakes, NJ, USA) with (for invasion) or without Matrigel (BD Biosciences) were used in the assay according to the manufacturer's protocols. The transfected cells were seeded in the upper chamber of the insert at a density of $1 \times 10^{4}$ cells in $200 \mu 1$ serum-free medium. The bottom of the inserts was incubated in the medium supplemented with $10 \%$ FBS. The cells were allowed to migrate for $40 \mathrm{~h}$ and invade for $60 \mathrm{~h}$. The cells that had migrated or invaded to the bottom of the inserts were stained with crystal violet and counted using a light microscope.

MTT assay. An MTT assay was performed to assess the cell proliferation ability of 786-O and ACHN cells in vitro. In each well of the 96-well plate, 5,000 cells were seeded and then transfected with 5 pmol miR-30b mimics, inhibitors, mimic NC or inhibitor NC. MTT (20 $\mu 1,5 \mathrm{mg} / \mathrm{ml}$; Sigma-Aldrich; Merck-Millipore, Darmstadt, Germany) was added into the wells to be detected at $0,24,48$ and $72 \mathrm{~h}$ post-transfection. Following this, the 96 -well plate was incubated at $37^{\circ} \mathrm{C}$ for $4 \mathrm{~h}$. The mixed medium was then replaced by $150 \mu$ l dimethyl sulfoxide (Sigma-Aldrich, Merck Millipore) and then agitated for $15 \mathrm{~min}$ at room temperature. Subsequently, the optical density (OD) of each well was measured by an ELISA microplate reader (Bio-Rad Laboratories, Inc., Hercules, CA, USA) at a wavelength of $490 \mathrm{~nm}$. 
Cell Counting Kit-8 (CCK-8) assay. Cell proliferation of 786-O and ACHN cells was also detected using the Cell Counting Kit-8 (Beyotime Institute of Biotechnology, Haimen, China) following the manufacturer's protocols. In each well of 96-well plate $\sim 5,000$ cells were seeded and $24 \mathrm{~h}$ later the cells were be transfected with 5 pmol miR-30b mimics, inhibitors, mimic $\mathrm{NC}$ or inhibitor NC. At $0,24,48$ and $72 \mathrm{~h}$ after transfection, $15 \mu \mathrm{l}$ CCK- 8 was added to the wells and OD of each well was measured after $1.5 \mathrm{~h}$ by an ELISA microplate reader (Bio-Rad Laboratories, Inc.) at a wavelength of $490 \mathrm{~nm}$.

Flow cytometry assay for apoptosis. The apoptosis rates of 786-O and ACHN cells in vitro were measured by performing a flow cytometry assay. A total of $\sim 3 \times 10^{5}$ cells were seeded in each well of a 6-well plate and then transfected with $200 \mathrm{pmol}$ miR-30b mimics, inhibitors, mimic NC or inhibitor NC. At $48 \mathrm{~h}$ post-transfection, all cells were harvested and washed twice with cold PBS. Subsequently, the cells were resuspended in $100 \mu \mathrm{l} 1 \mathrm{X}$ binding buffer, and $5 \mu \mathrm{l}$ Annexin V-fluorescein isothiocyanate (Invitrogen; Thermo Fisher Scientific, Inc.) and $5 \mu 1$ propidium iodide (Invitrogen; Thermo Fisher Scientific, Inc.) were added into each cell suspension. After $15 \mathrm{~min}$, $400 \mu \mathrm{l}$ binding buffer was added to each tube and flow cytometry (EPICS XL 4; Beckman Coulter, Inc., Brea, CA, USA) was used to quantify and analyze the apoptosis rate. FlowJo software (version, X) fl (FlowJo LLC, Ashland, OR) was used.

Hoechst 33342 staining assay. Cell apoptosis was observed using a Hoechst 33342 staining assay. After 48 h transfection, $\sim 1 \times 10^{5}$ cells were cultured in a six-well plates and were washed with PBS and stained with Hoechst $33342(5 \mu \mathrm{g} / \mathrm{ml}$; Thermo Fisher Scientific, Inc.) for $10 \mathrm{~min}$. Following washing with PBS twice, images of the cells were acquired with a fluorescence microscope.

Statistical analysis. A paired Student's t-test was used to compare the expression levels of miR-30b in matching tissues. Student's $t$-test was used to analyze assays for characterizing phenotypes of cells. The association between the expression level of miR-30b and clinical clinicopathological parameters was analyzed by Fisher's exact test or $\chi^{2}$ test. All statistical analysis was conducted by SPSS software (version, 19.0; IBM SPSS. Armonk, NY, USA). P $<0.05$ was considered to indicate a statistically significant difference.

\section{Results}

miR-30b was upregulated in RCC tissues and cell lines. To determine the expression of miR-30b in RCC tissues and cell lines, RT-qPCR was performed in RCC cell lines and 31 paired tissues. The ratios of miR-30b in 31 paired tissues $\left[\log _{2}\right.$ ratio $\left.(\mathrm{T} / \mathrm{N})\right]$ are presented in Fig. 1A, in which miR-30b was upregulated in $20 \mathrm{RCC}$ tissues. The results demonstrated that the expression of miR-30b in RCC tissues (mean relative expression $=6.83$ ) was significantly higher than normal tissues $(\mathrm{P}=0.009)$. Relative expression of miR-30b in paired tissues is presented in Fig. 1B. The expression levels of miR-30b in RCC cell lines (786-O, ACHN and 769-P) were significantly higher when compared with the 293T human embryo kidney cell line (786-O, $\mathrm{P}=0.032$; $\mathrm{ACHN}, \mathrm{P}=0.012 ; 769-\mathrm{P}, \mathrm{P}=0.006$ ),
Table I. Clinicopathological features of renal cell carcinoma patients.

\begin{tabular}{lc} 
Characteristic & Number of ca \\
\hline $\begin{array}{l}\text { Mean age/age range (years) } \\
\text { Gender }\end{array}$ & $50 / 25-70$ \\
$\quad$ Male/female & $19 / 12$ \\
Histological type & \\
$\quad$ Clear cell/papillary & $26 / 5$ \\
pT-stage & \\
T1/T2/T3+T4 & $16 / 11 / 4$ \\
Fuhrman grade & \\
I/II/III/IV & $10 / 14 / 4 / 3$ \\
AJCC clinical stages & \\
I/II/III+IV & $16 / 12 / 3$
\end{tabular}

pT, primary tumor; AJCC, American Joint Committee on Cancer.

as indicated in Fig. 1C. The results suggest that miR-30b may function as an oncogene in RCC.

Association between the expression level of miR-30b and clinicopathological characteristics in RCC patients. Patients were divided into two groups (high expression and low expression groups) according to the mean expression level of miR-30b. Fisher's exact test or $\chi^{2}$ test was performed to investigate the association between the expression and clinicopathological characteristics of patients. No association was observed between the expression of miR-30b and the age, gender, $\mathrm{T}$ stage, histological type, Fuhrman grade and American Joint Committee on Cancer clinical stages (all $\mathrm{P}>0.05$ ). However, the validity of the results must be questioned due to the low number of experimental cases; the results should be verified in future studies (Data not shown).

Validation of cell transfection efficiency. RT-qPCR was performed to quantify the transfection efficiency of miR-30b mimics or inhibitors compared with mimic NC or inhibitor NC. The results indicated that the expression levels of miR-30b in the miR-30b mimic group were 271.58-fold higher (786-O) and 417.68-fold higher (ACHN) when compared with the negative control group ( $\mathrm{P}=0.005$ 786- $\mathrm{O}, \mathrm{P}=0.008, \mathrm{ACHN})$, and expression in the inhibitor group was 0.38 times (786-O) and 0.40 times of the inhibitor $\mathrm{NC}$ group $(\mathrm{P}=0.002$ 786-O, $\mathrm{P}=0.008$ ACHN, Fig. 1D).

miR-30b promotes cell proliferation. Cell proliferation was measured using MTT and CCK-8 assays in vitro. The results of MTT and CCK-8 assay suggested that upregulation of miR-30b promoted cell proliferation, whereas downregulation of miR-30b attenuated cell proliferation. As demonstrated in Fig. 2A, the CCK-8 assay reduced cell proliferation of 786-O cells in the inhibitor group by $13.76 \%(\mathrm{P}>0.05), 16.01 \%$ $(\mathrm{P}=0.002), 17.78 \%(\mathrm{P}=0.048)$, while the mimic group was promoted by $0.64 \%(\mathrm{P}>0.05), 23.75 \%(\mathrm{P}=0.013), 10.90 \%$ $(\mathrm{P}=0.047)$, after transfection at $0,24,48$ and $72 \mathrm{~h}$, respectively, 
Table II. Sequences used in the present study.

\begin{tabular}{ll}
\hline Gene & \\
\hline miR-30b mimic & Sequence \\
NC & Sense: 5'-UGUAAACAUCCUACACUCAGCU-3' \\
& Antisense:5'-CUGAGUGUAGGAUGUUUACAUU-3' \\
miR-30b inhibitor & Sense: 5'-UUCUCCGAACGUGUCACGUTT-3' \\
Inhibitor NC & Antisense: 5'-ACGUGACACGUUCGGAGAATT-3' \\
miR-30b forward primer & 5'-AGCUGAGUGUAGGAUGUUUACA-3' \\
U6 forward primer & 5'-CAGUACUUUUGUGUAGUACAA-3' \\
U6 reverse primer & 5'-TGTAAACATCCTACACTCAGCT-3' \\
\end{tabular}

miR, microRNA; NC, negative control.

A

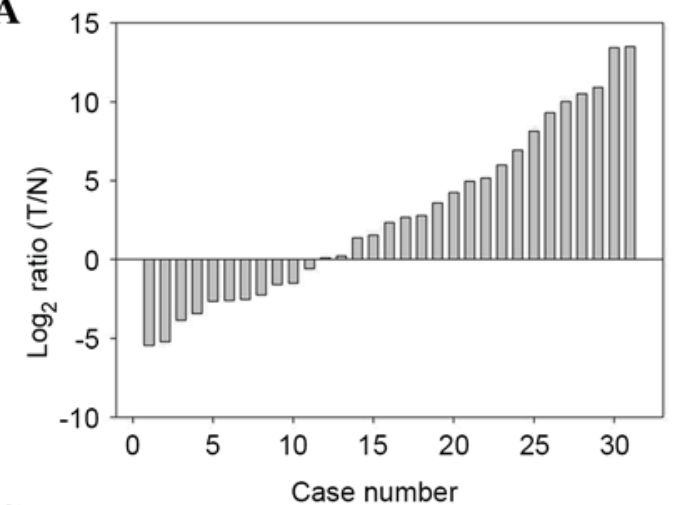

C

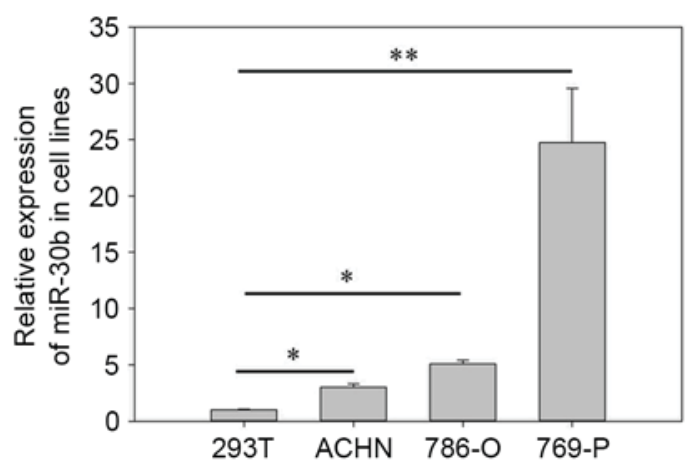

B

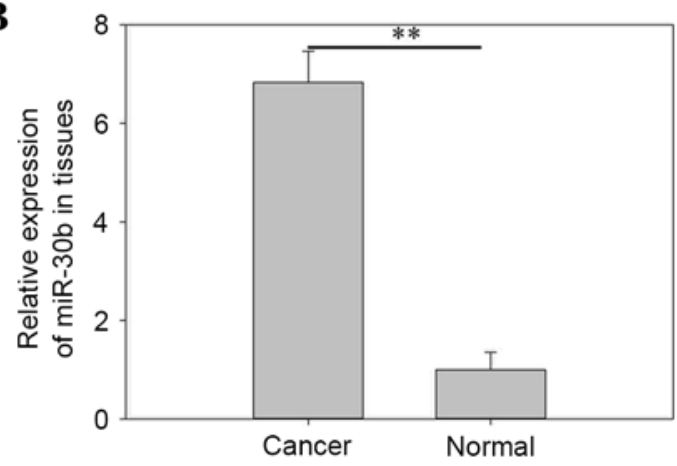

D

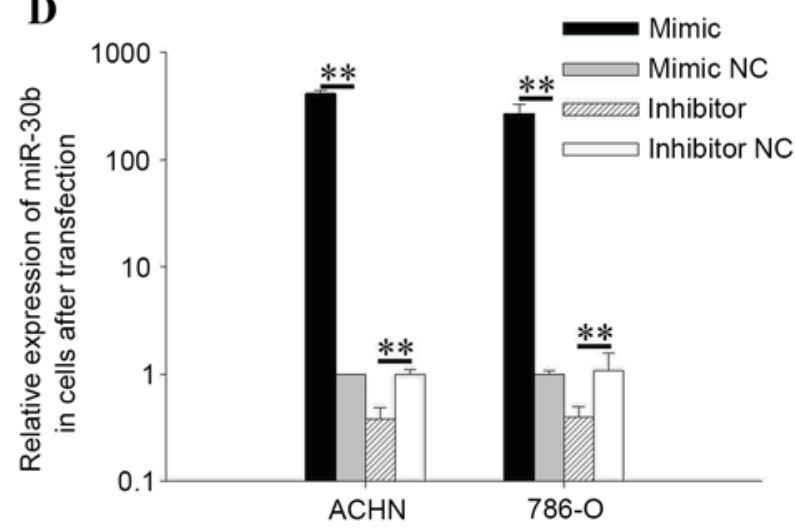

Figure 1. Expression of miR-30b in 31 paired RCC tissues and adjacent normal tissues. (A) $\log _{2}$ ratios (T/N) of miR-30b in 31 paired tissues. (B) The relative expression of miR-30b in RCC and normal tissues. ${ }^{* *} \mathrm{P}<0.01$ vs. normal. (C) The relative expression of miR-30b in RCC cell lines. ${ }^{*} \mathrm{P}<0.05$, ${ }^{* *} \mathrm{P}<0.01 \mathrm{vs}$. $293 \mathrm{~T}$. (D) The expression of miR-30b in 786-O and ACHN cells following transfection with mimics, inhibitors, or their respective NC. ${ }^{* *} \mathrm{P}<0.01$ vs. respective NC. RCC, renal cell carcinoma; T, RCC tissues; N, normal tissues; miR-30b, microRNA-30b; NC, negative control.

compared with those transfected with the respective inhibitor NC or mimic NC. Similarly, the MTT assay (Fig. 2B) demonstrated that cell proliferation of 786-O cells in the inhibitor group was reduced by $2.70 \%(\mathrm{P}>0.05), 11.94 \%(\mathrm{P}=0.009)$, $9.78 \%(\mathrm{P}=0.0002)$, with the mimic group promoted by $2.31 \%$ $(\mathrm{P}>0.05), 12.86 \%(\mathrm{P}=0.006), 14.98 \% \quad(\mathrm{P}=0.015)$ compared with the inhibitor NC or mimic NC group at 24, 48 and $72 \mathrm{~h}$ post-transfection, respectively.

In ACHN cells, the results demonstrated that cell proliferation of cells transfected with the miR-30b inhibitor was reduced by $17.43 \%(\mathrm{P}=0.002), 21.59 \%(\mathrm{P}=0.004), 16.41 \%$ $(\mathrm{P}=0.011)$ in CCK-8 assay (Fig. 2C) and $12.12 \%(\mathrm{P}>0.05)$, $10.76 \%(\mathrm{P}=0.009), 7.11 \%(\mathrm{P}=0.0003)$ in MTT (Fig. 2D) after transfection at 24,48 and $72 \mathrm{~h}$ compared with cells transfected with inhibitor NC. Inversely, the proliferation of ACHN cells transfected with miR-30b mimic was promoted by $11.86 \%$ $(\mathrm{P}=0.018), 14.97 \%(\mathrm{P}=0.0007), 12.36 \%(\mathrm{P}=0.037)$ in $\mathrm{CCK}-8$ assay (Fig. 2C), with $12.59(\mathrm{P}=0.031), 10.16 \%(\mathrm{P}=0.005)$, $22.45 \%(\mathrm{P}=0.001)$ in MTT assay (Fig. 2D) at 24, 48 and $72 \mathrm{~h}$, respectively, compared with cells transfected with mimic NC. 
A

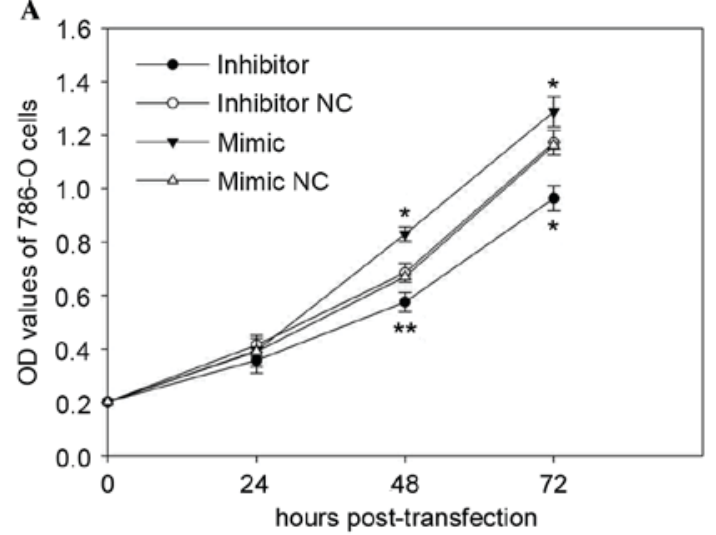

C

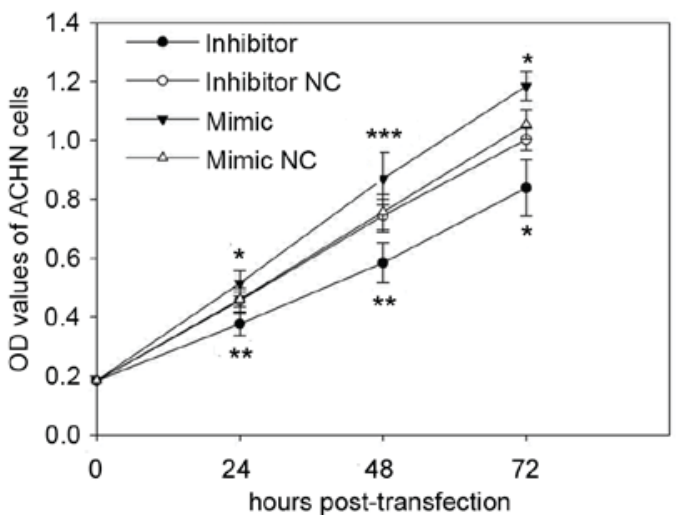

B

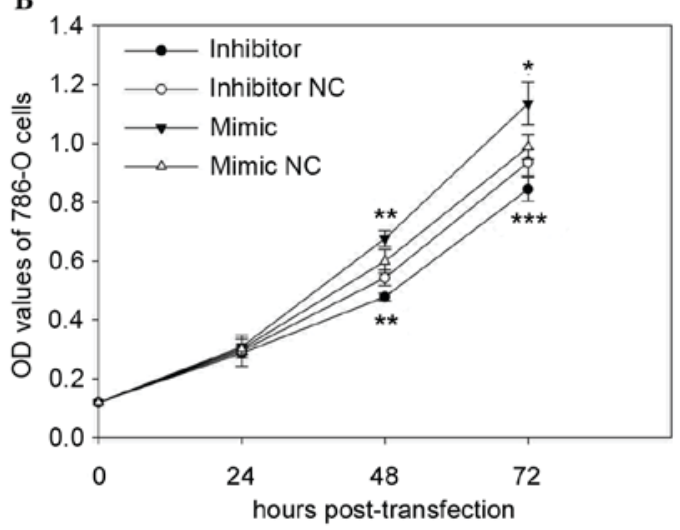

D

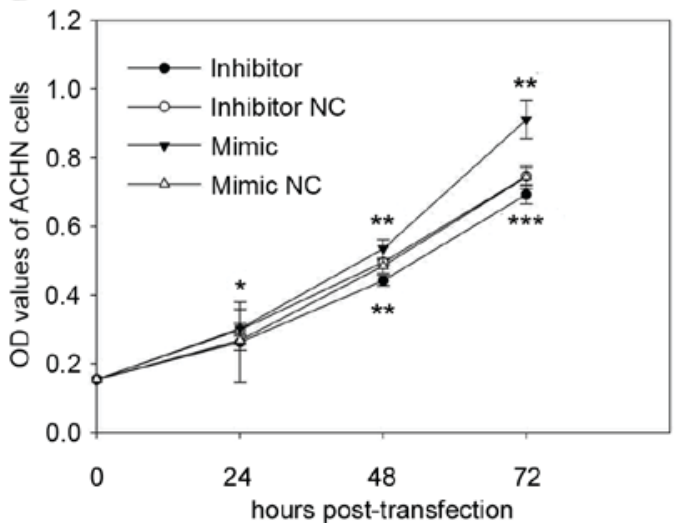

Figure 2. Cell proliferation assay of 786-O and ACHN cells. Cell proliferation of (A and B) 786-O and (C and D) ACHN cells transfected with an miR-30b mimic, inhibitor, inhibitor NC or mimic NC was measured by (A and C) CCK-8 and (B and D) MTT assay analysis. ${ }^{*} \mathrm{P}<0.05,{ }^{* * *} \mathrm{P}<0.01,{ }^{* * * *} \mathrm{P}<0.001 \mathrm{vs}$. their respective NC. miR-30b, microRNA-30b; NC, negative control; OD, optical density.

miR-30b promoted RCC cell mobility. In order to investigate the effect of miR-30b on cell mobility in RCC cell lines (786-O and $\mathrm{ACHN}$ ), Transwell invasion, migration and wound scratch assays were performed. As demonstrated in Fig. 3A and B, the results of the wound scratch assay of 786-O indicated that the migratory distance of cells transfected with miR-30b inhibitor was reduced significantly by $40.58 \%(\mathrm{P}=0.001)$ at $24 \mathrm{~h}$ post-transfection compared with cells transfected with inhibitor NC. In contrast, upregulation of miR-30b by transfecting the miR-30b mimic promoted migratory distances by $63.45 \%(\mathrm{P}=0.003)$ in $786-\mathrm{O}$ at $24 \mathrm{~h}$ post-transfection compared with cells transfected with mimic NC. In ACHN cells, the downregulation of miR-30b reduced the migratory distance by $20.68 \%(\mathrm{P}=0.001)$ at $24 \mathrm{~h}$ post-transfection (Fig. 3A and $\mathrm{C}$ ). By contrast, upregulation of miR-30b promoted migratory distances by $35.64 \%(\mathrm{P}=0.008)$ in $\mathrm{ACHN}$ cells at $24 \mathrm{~h}$ post-transfection (Fig. 3A and C).

As indicated in Fig. 4, the results demonstrated that the invasive ability of 786-O cells transfected with miR-30b inhibitors was reduced significantly by $36.80 \%(\mathrm{P}=0.003)$ when compared with cells transfected with inhibitor $\mathrm{NC}$, and promoted by $50.09 \%$ in the miR-30b mimic group $(\mathrm{P}=0.002)$ when compared with the mimic NC group (Fig. 4A and B). The migratory ability of 786-O cells transfected with miR-30b inhibitors was reduced by $47.54 \%(\mathrm{P}=0.004)$ and promoted by $60.95 \%(\mathrm{P}=0.003)$ in cells transfected with miR-30b mimic, when compared with the inhibitor NC or mimic NC group (Fig. 4A and C). In ACHN cells, the Transwell invasion assay demonstrated that the invasive ability of cells transfected with miR-30b mimic was increased by $39.60 \%(\mathrm{P}=0.004)$ and reduced by $38.78 \%(\mathrm{P}=0.004)$ in cells transfected with miR-30b inhibitor compared with the mimic NC or inhibitor NC group (Fig. 5A and B). As indicated in Fig. 5A and C, the migratory ability of cells transfected with miR-30b mimic was increased by $40.93 \%(\mathrm{P}=0.003)$ and reduced by $33.54 \%(\mathrm{P}=0.006)$ in cells transfected with miR-30b inhibitor, compared with cells transfected with mimic NC or inhibitor NC. The results of the Transwell invasion, migration and wound scratch assays indicated that miR-30b promoted the ability of RCC cell mobility.

miR-30b suppressed apoptosis. Apoptosis rate was qualified by flow cytometry and Hoechst 33342 staining assay. The results of the flow cytometry indicated that miR-30b had a negative effect on apoptosis, as the upregulation of miR-30b suppressed apoptosis while downregulation of miR-30b invoked apoptosis in RCC cells (Figs. 6 and 7). After a $48 \mathrm{~h}$ transfection of the miR-30b mimic, inhibitor, mimic NC or inhibitor $\mathrm{NC}$, all cells were collected for measurement. As presented in Fig. 6C, the results demonstrated that the early apoptosis rate of cells transfected with miR-30b inhibitor or inhibitor $\mathrm{NC}$ was $25.74 \pm 3.55$ vs. $7.71 \pm 2.04(\mathrm{P}=0.025)$ in $786-\mathrm{O}$ cells. Fig. 7C demonstrated that the apoptotic rate of ACHN cells was $27.76 \pm 0.42$ vs. $11.88 \pm 0.42 \%(\mathrm{P}=0.0002)$, while upregulation of miR-30b by transfection the miR-30b mimic reduced the apoptotic rate from $14.81 \pm 1.62$ to $3.64 \pm 0.71 \%(\mathrm{P}=0.003)$ in 7860 cells (Fig. 6D) and $15.80 \pm 0.57$ to $7.78 \pm 0.60 \%(P=0.002)$ 


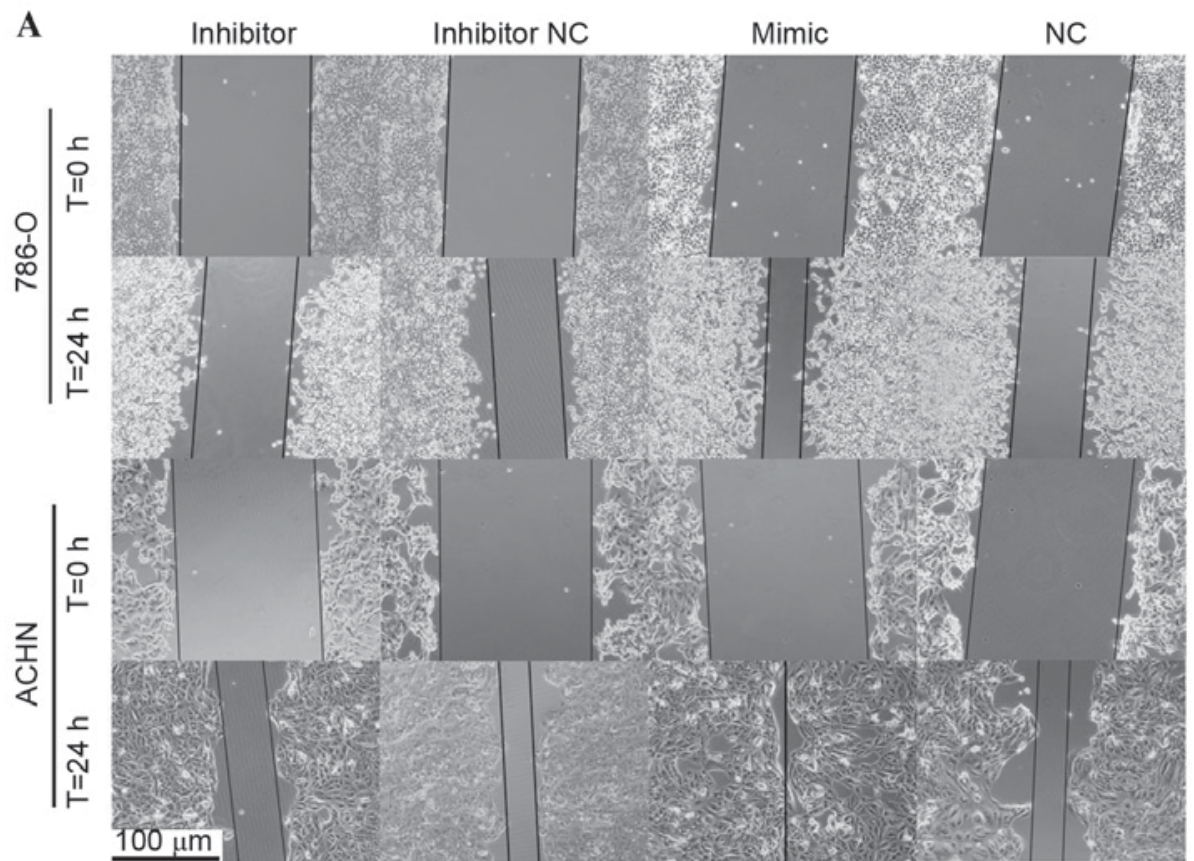

\section{B}
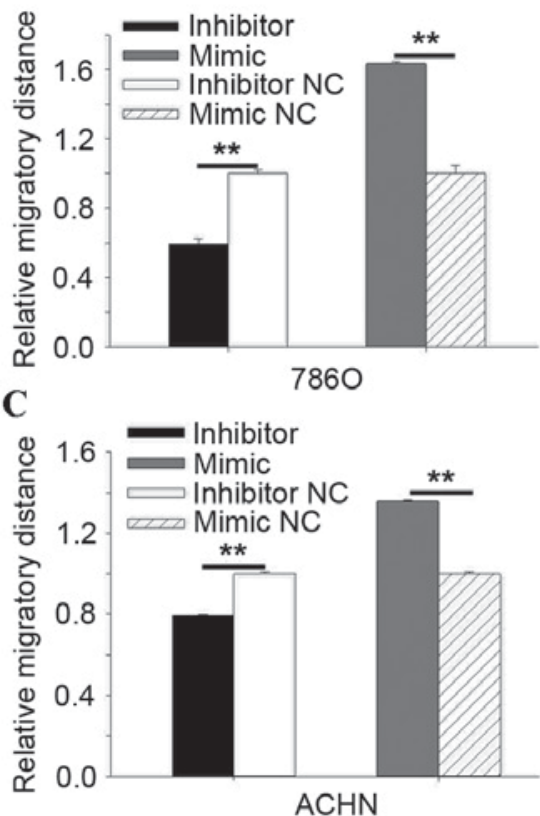

Figure 3. Wound scratch assay of 786-O and ACHN cells. (A) Images captured of the wound scratch assay. (B) Cell migratory distances of 786-O cells after transfection of an miR-30b mimic, inhibitor, inhibitor NC or mimic NC. (C) Cell migratory distances in ACHN cells following transfection. ${ }^{* * *} \mathrm{P}<0.01 \mathrm{vs.} \mathrm{NC}$. miR-30b, microRNA-30b; NC, negative control.

A

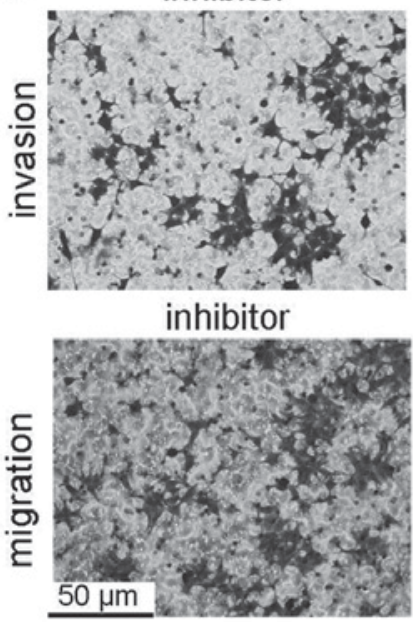

inhibitor NC

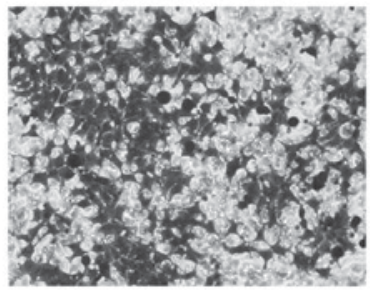

inhibitor NC

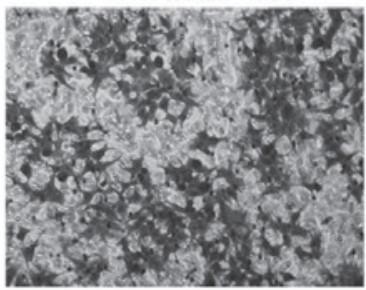

mimic

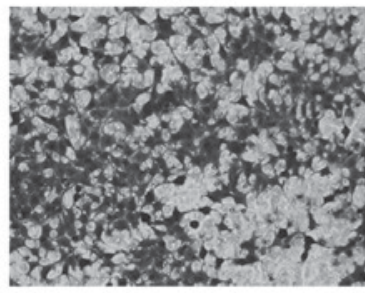

mimic

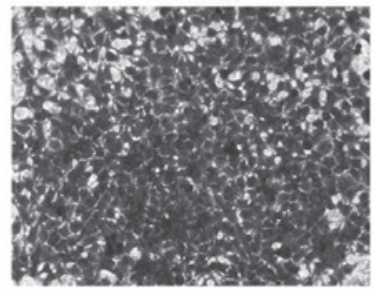

mimic NC

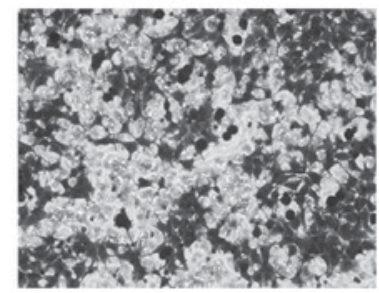

mimic NC

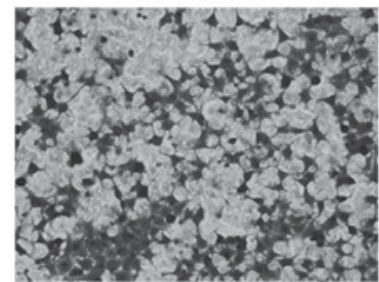

B

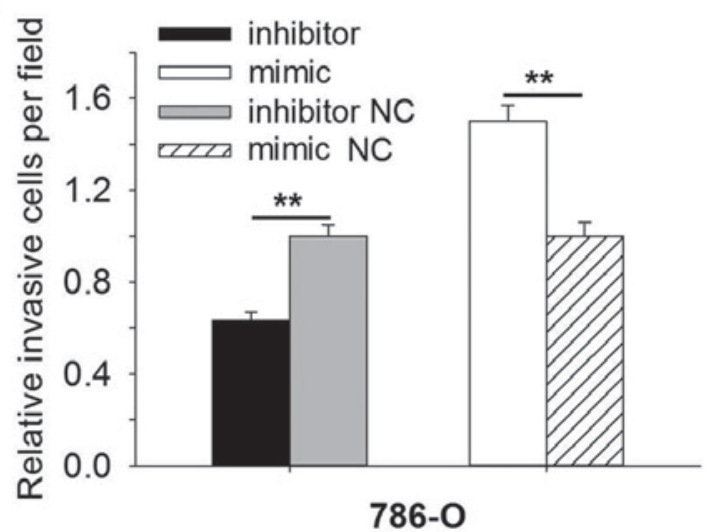

C

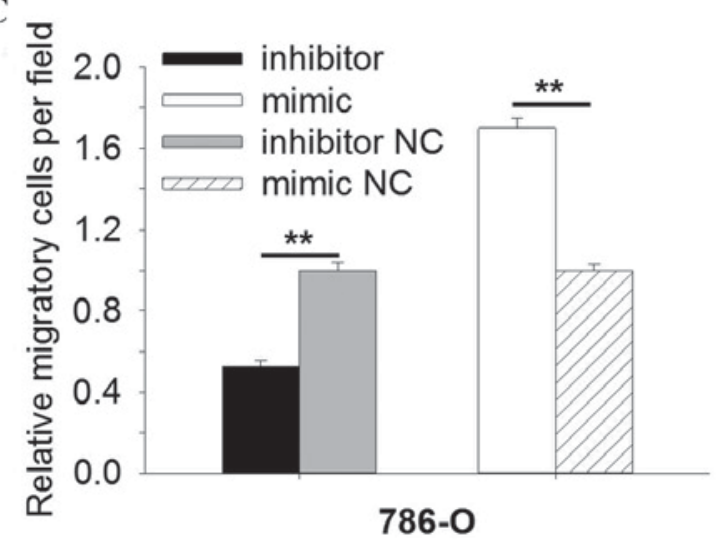

Figure 4. Migration and Transwell invasion assay analysis of migration and invasion in 786-O cells. (A) Images captured of migration and invasion. (B) Upregulation of miR-30b promoted invasion ability and downregulation of miR-30b inhibited invasion ability of 786-O cells. (C) The same results can be observed in the Transwell migration assay. ${ }^{* *} \mathrm{P}<0.01$ vs. NC. miR-30b, microRNA-30b; NC, negative control. 
A
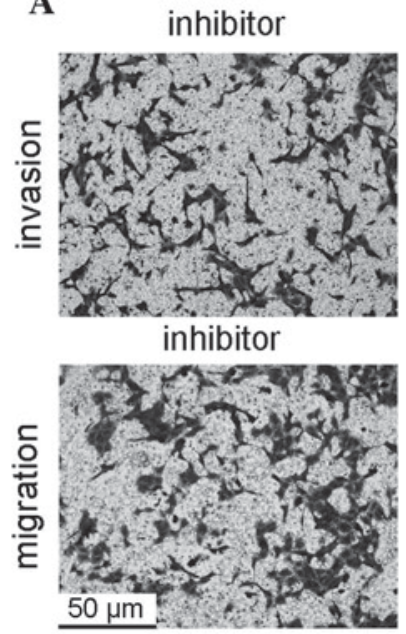

inhibitor NC

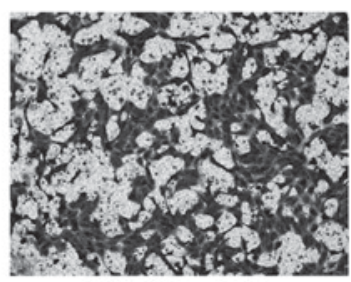
inhibitor NC

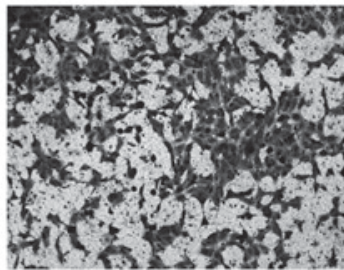

B

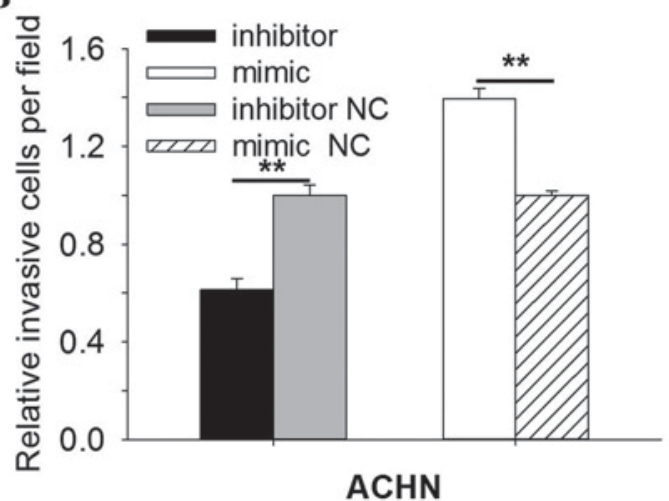

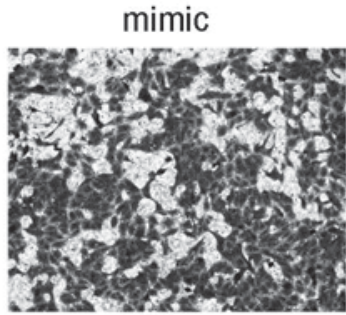
mimic
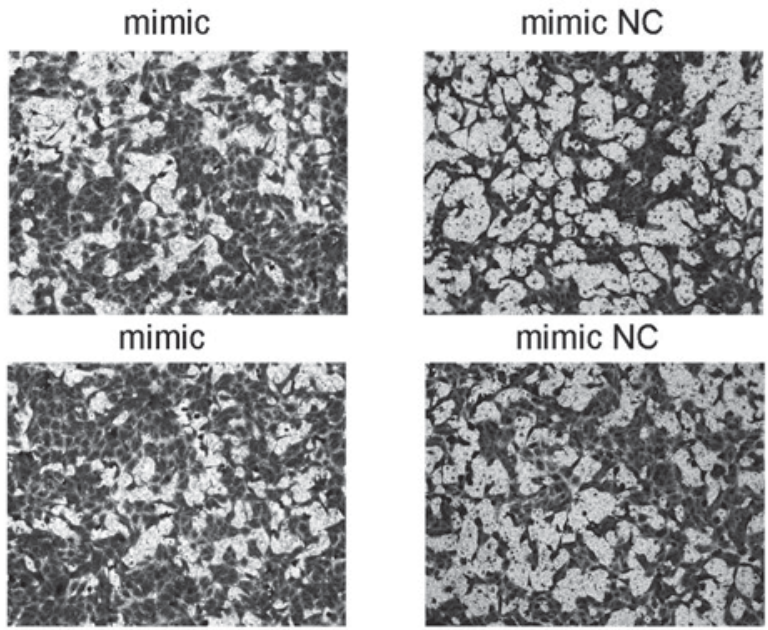

mimic NC

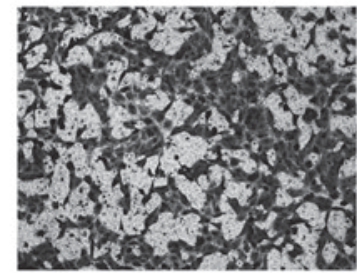

C

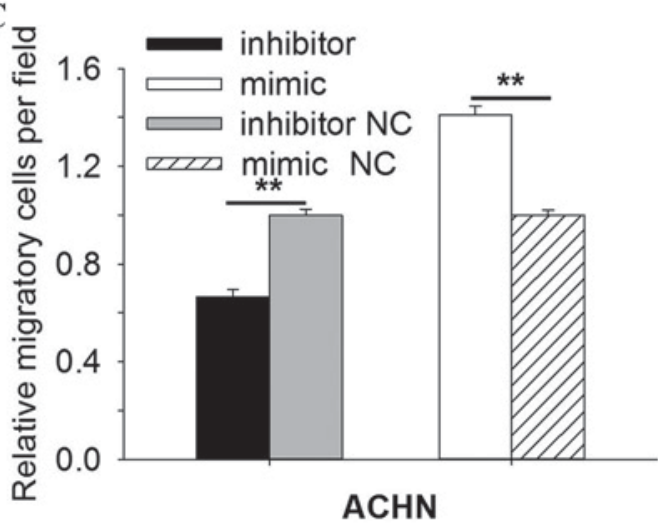

Figure 5. Migration and Transwell invasion assay analysis of migration and invasion in ACHN cells. (A) Images captured of migration and invasion. (B) Upregulation of miR-30b promoted invasion ability and downregulation of miR-30b inhibited invasion ability of ACHN cells. (C) The same results can be observed in the Transwell migration assay. ${ }^{* *} \mathrm{P}<0.01$ vs. NC. miR-30b, microRNA-30b; NC, negative control.

in ACHN cells (Fig. 7D), respectively. The results of the present study demonstrated that upregulation of miR-30b may inhibit cell apoptosis, while downregulation of miR-30b may induce apoptosis in RCC cells.

The results of Hoechst 33342 staining assay are consistent with results of the flow cytometry. As indicated in Fig. 8A, the apoptotic rate of 786-O cells was $47.33 \%$ in the inhibitor group and $30.78 \%$ in the inhibitor NC group $(\mathrm{P}=0.011)$. The apoptotic rate in cells transfected with the miR-30b mimic was $13.39 \%$, and $32.27 \%$ in cells transfected with the miR-30b mimic NC $(\mathrm{P}=0.0001)$. The results indicated that $\mathrm{miR}-30 \mathrm{~b}$ may inhibit cell apoptosis. In ACHN cells transfected with the miR-30b inhibitor, the apoptotic rate was 36.80, and $25.89 \%$ in cells transfected with inhibitor NC $(\mathrm{P}=0.003)$. The apoptotic rate of cells transfected with the miR-30b mimic and mimic $\mathrm{NC}$ was 11.93 and $27.17 \%$, respectively $(\mathrm{P}=0.008$; Fig. 8B). The results demonstrated that miR-30b may regulate RCC cell apoptosis.

\section{Discussion}

The identification of biomarkers for the diagnosis of cancer may lead to more efficient treatment and lower mortality rates (19). However, there are currently no reliable biomarkers for patients with RCC. MicroRNAs have been identified as a potential source of cancer biomarkers, due to their abnormal expression in numerous types of cancers.

Tumorigenesis is associated with activation of oncogenes and dysfunction of anti-oncogenes. MicroRNAs may serve an important role as either as an oncogene or tumor suppressor gene via regulating the expression of oncogenes or anti-oncogenes at post-transcription level (20). Upregulated microRNAs could act as oncogenes, the downregulated microRNAs as tumor suppressors.

miR-30b has been previously described as a tumor suppressor in certain types of cancer, including NSCLC, gastric cancer and colorectal cancer (CRC) $(14,21,22)$. Conversely, miR-30b has been described as an oncogene in bladder cancer (23), oral squamous cell cancer (10) and medulloblastoma (24). However, the function of miR-30b in RCC remains to be elucidated. Previous microarray studies have indicated different levels of expression of miR-30b in RCC, which may result from the high sensitivity and limited number of sample tissues $(16,17)$. Another previous study revealed that the deregulation of miR-30 family (miR-30a, miR-30b and miR-30c) was correlated with distant metastasis (25). Thus, in the present study, RT-qPCR was performed to detect the expression level of miR-30b in RCC tissues and cell lines. The association between expression of miR-30b and clinicopathological characteristic was also investigated in the current 

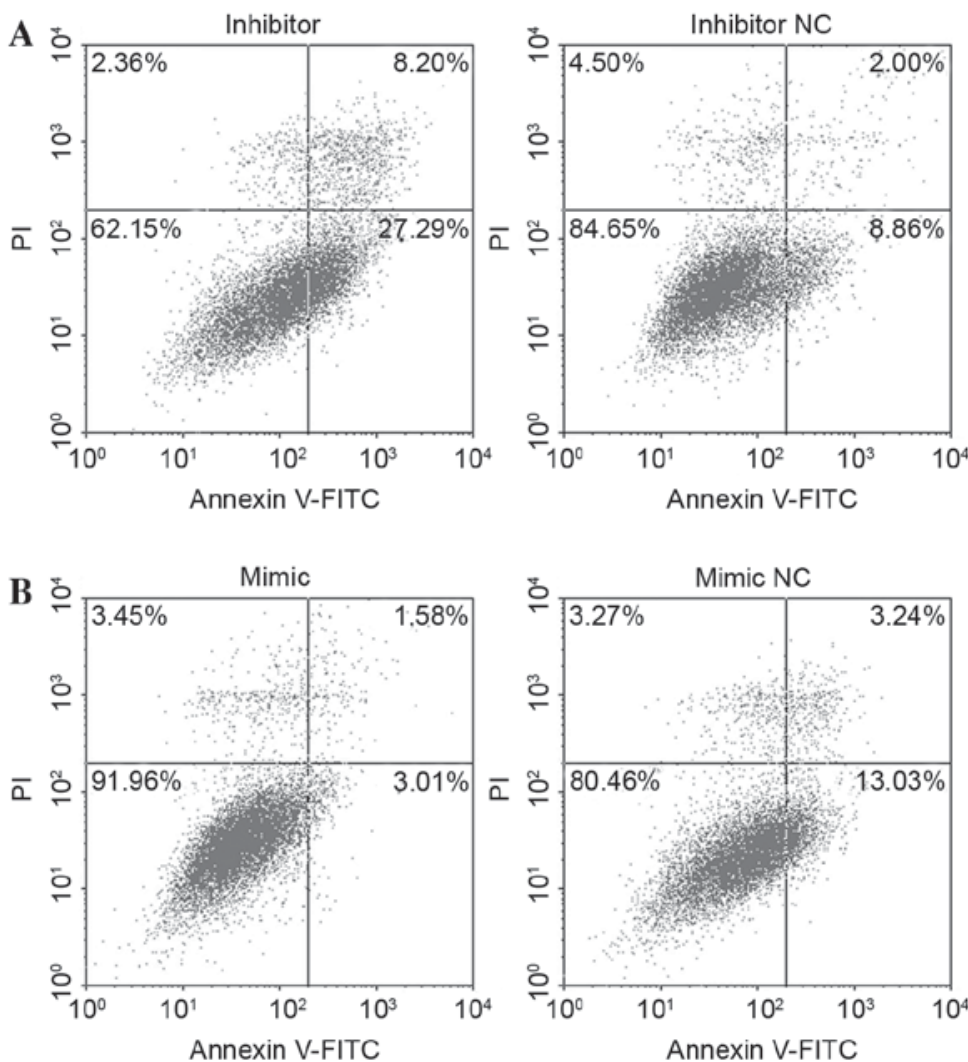

C

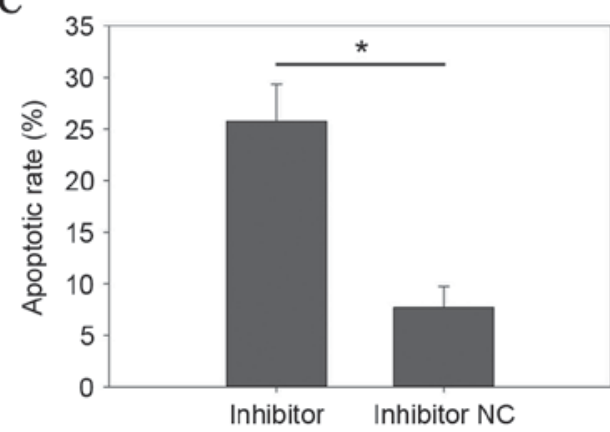

D

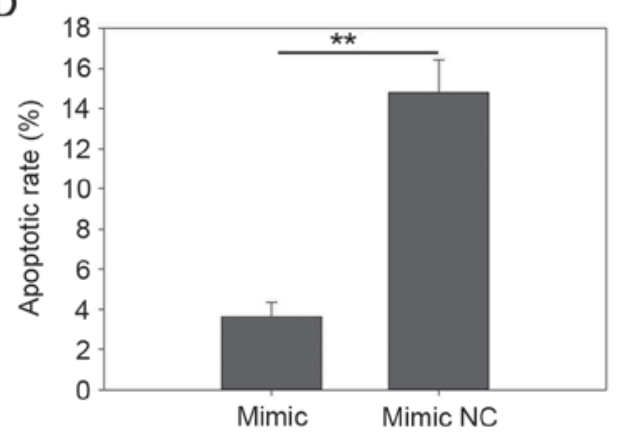

Figure 6. Flow cytometry analysis of apoptosis in 786-O cells. (A and C) Downregulation of miR-30b induced cell apoptosis while (B and D) upregulation of miR-30b could inhibit cell apoptosis. ${ }^{*} \mathrm{P}<0.05,{ }^{* *} \mathrm{P}<0.01$ vs. respective NC. miR-30b, microRNA-30b; PI, propidium iodide; FITC, fluorescein isothiocyanate; NC, negative control.
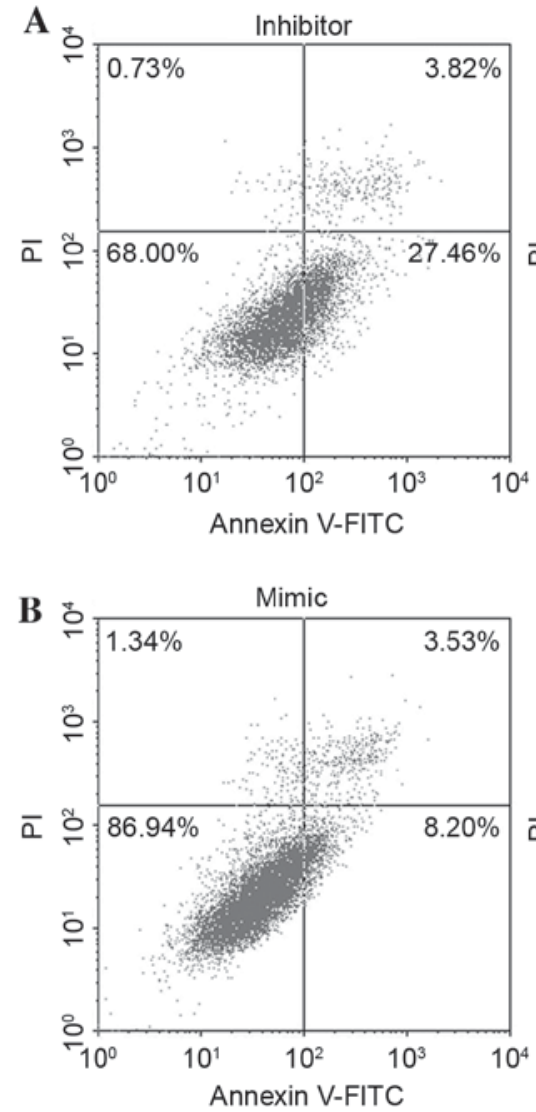
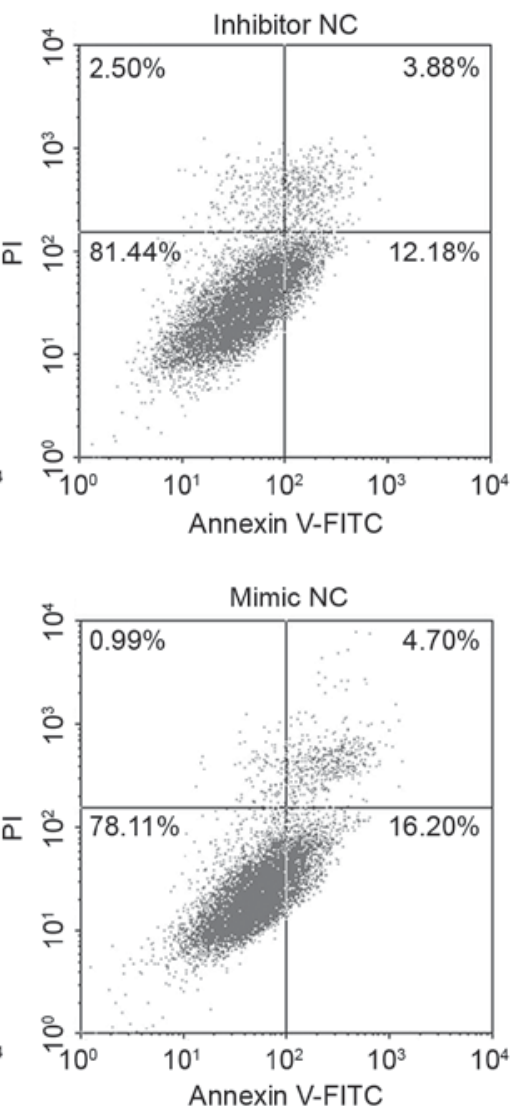

C

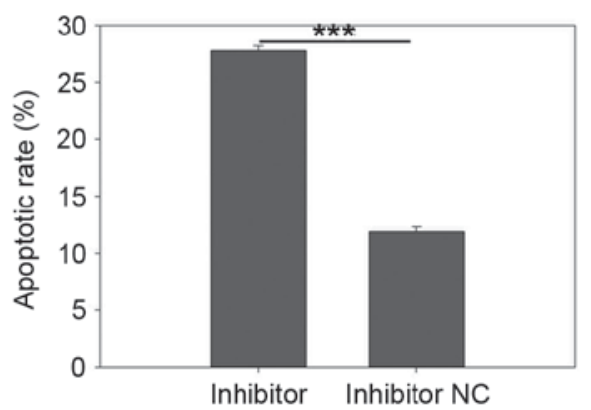

D

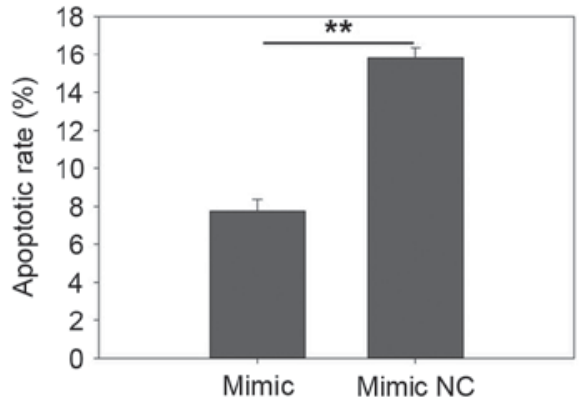

Figure 7. Flow cytometry analysis of apoptosis in ACHN cells. (A and C) Downregulation of miR-30b with an inhibitor increased apoptotic rate, while (B and D) upregulation suppressed apoptotic rate. ${ }^{* *} \mathrm{P}<0.01,{ }^{* * *} \mathrm{P}<0.001$. miR-30b, microRNA-30b; PI, propidium iodide; FITC, fluorescein isothiocyanate; NC, negative control. 

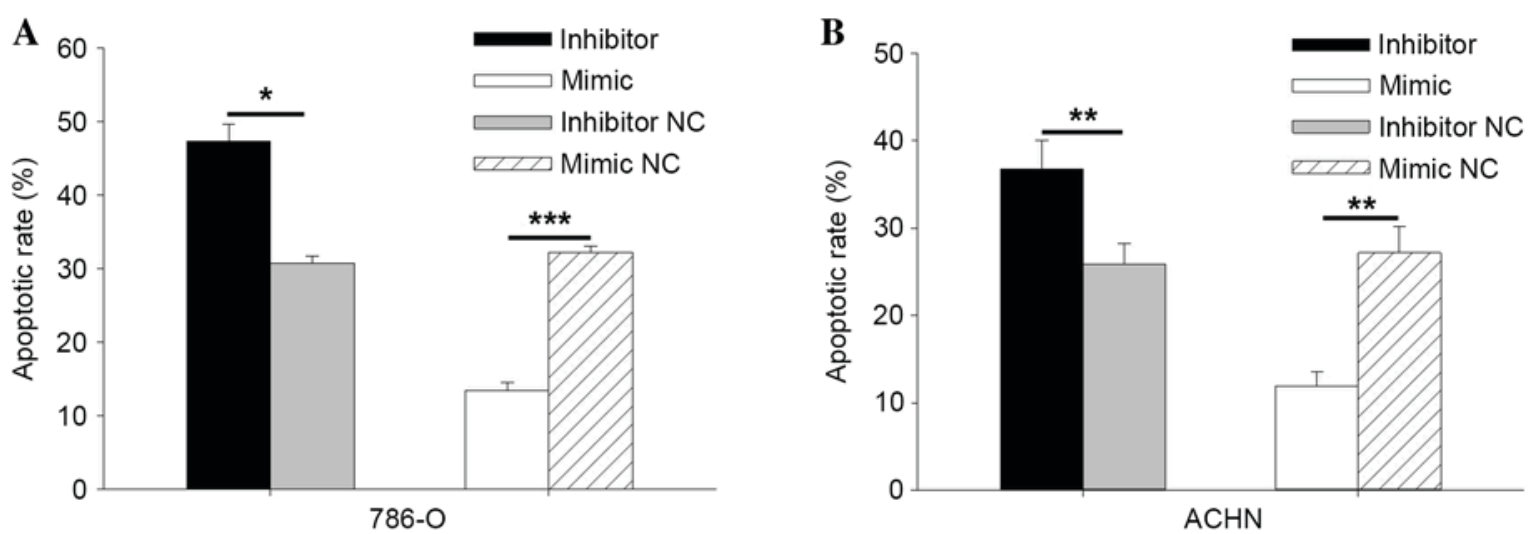

Figure 8. Hoechst 33342 staining to determine apoptotic rate in (A) 786-O and (B) ACHN cells. Staining was conducted $48 \mathrm{~h}$ following transfection with an miR-30b mimic, inhibitor or respective negative control. ${ }^{*} \mathrm{P}<0.05,{ }^{* *} \mathrm{P}<0.01 ;{ }^{* * *} \mathrm{P}<0.001$. miR-30b, microRNA-30b; NC, negative control.

study. The function of miR-30b in RCC cell lines was investigated by performing MTT, CCK-8, Transwell, wound scratch, Hoechst 33342 staining and flow cytometry assays. The results revealed that miR-30b was upregulated in RCC tissues and cell lines (ACHN, 786-O and 769-P) when compared with adjacent normal tissues and 293T cells. In addition, miR-30b may regulate RCC cell proliferation, migration, invasion and apoptosis. All the results suggested miR-30b acts as an oncogene in RCC. No association was identified between the expression of miR-30b and the clinicopathological characteristics observed in patients. The present study is, to the best of our knowledge, the first to describe miR-30b as an oncogene in RCC.

In certain types of cancer, the mechanism of miR-30b is understood. Tian et al (22) demonstrated that miR-30b regulated gastric cancer cell processes by targeting eukaryotic translation initiation factor 5A2. In gastric cancer, Zhu et al (15) indicated that miR-30b could promote cell apoptosis and suppress tumor growth in vivo by targeting plasminogen activator inhibitor-1. In addition, it has been reported that DNA (cytosine-5)-methyltransferase 1 may suppress miR-30b expression partly via methylation of its promoter (12). In NSCLC, miR-30b may target the collagen triple helix repeat containing 1 protein to inhibit cell invasion and migration (13). Gu et al (26) identified that patients with low miR-30b expression in NSCLC had a lower overall survival rate, which indicated that miR-30b could be selected as a biomarker for NSCLC. Furthermore, it was reported that miR-30b could regulate migration and invasion of CRC by targeting SIX homeobox 1 (14). In CRC, miR-30b was also reported to serve a role as a tumor suppressor by targeting the KRAS proto-oncogene GTPase, phosphatidylinositol-4,5-bisphosphate 3-kinase catalytic subunit $\delta$ and B-cell lymphoma 2 genes (27).

A previous study identified that the miR-30 family may modulate endothelial cell behavior during angiogenesis by targeting delta-like 4 (28). Another previous study reported that the expression of miR-30 family is inversely correlated with MYB proto-oncogene like 2 in acute myeloid leukemia patients (29). Furthermore, miR-30b has been demonstrated to be associated with cancer therapy. It has been reported that overexpression miR-30b may improve p53 gene therapy for laryngeal carcinoma (30). In breast cancer cells, trastuzumab produces therapeutic actions by upregulating miR-30b and miR-26a (31). These findings suggest that miR-30b is closely associated with tumorigenesis, where it acts as an oncogene or anti-oncogene.

The underlying mechanism of miR-30b in RCC requires further elucidation. The present study demonstrated its role as an oncogene in RCC. The overexpression may promote RCC cell proliferation, migration, invasion and inhibit cell apoptosis. Whilst the downregulation of miR-30b could inhibit RCC cell proliferation, migration, invasion and promote cell apoptosis. Thus, miR-30b has the potential to be an effective biomarker of RCC.

In conclusion, the current study is the first to describe miR-30b as an oncogene within RCC, in addition to identifying that miR-30b could regulate cell proliferation, migration, invasion and apoptosis. Further research should focus on the underlying mechanism of miR-30b in RCC, and on investigating the possible use of miR-30 as a biomarker for RCC.

\section{Acknowledgements}

The present study was supported by the National Natural Science Foundation of China (grant no. 81101922), the Science and Technology Development Fund Project of Shenzhen (grant nos. JCYJ20130402114702124 and JCYJ20150403091443329) and the Fund of Guangdong Key Medical Subject.

\section{References}

1. Laitinen M, Parry M, Ratasvuori M, Wedin R, Albergo JI, Jeys L, Abudu A, Carter S, Gaston L, Tillman R and Grimer R: Survival and complications of skeletal reconstructions after surgical treatment of bony metastatic renal cell carcinoma. EJSO the Journal Cancer Surgery 41: 886-892, 2015.

2. Siegel R, Naishadham D and Jemal A: Cancer statistics, 2013. CA Cancer J Clin 63: 11-30, 2013.

3. Rasmussen F: Metastatic renal cell cancer. Cancer Imaging 13: 374-380, 2013.

4. Rouvière O, Bouvier R, Négrier S, Badet L and Lyonnet D: Nonmetastatic renal-cell carcinoma: Is it really possible to define rational guidelines for post-treatment follow-up? Nat Clin Pract Oncol 3: 200-213, 2006.

5. Bianchi M, Sun M, Jeldres C, Shariat SF, Trinh QD, Briganti A, Tian Z, Schmitges J, Graefen M, Perrotte P, et al: Distribution of metastatic sites in renal cell carcinoma: A population-based analysis. Ann Oncol 23: 973-980, 2012. 
6. Wang Q, Zhang W, Yang J, Liu YL, Yan ZX, Guo ZJ, Li YJ and Bian XW: High ERa36 Expression level and membrane location predict poor prognosis in renal cell carcinoma. Medicine (Baltimore) 94: e1048, 2015.

7. Zhang HM, Yang FQ, Chen SJ, Che J and Zheng JH: Upregulation of long non-coding RNA MALAT1 correlates with tumor progression and poor prognosis in clear cell renal cell carcinoma. Tumour Biol 36: 2947-2955, 2015.

8. Schaefer A, Jung M, Kristiansen G, Lein M, Schrader M, Miller K, Stephan C and Jung K: MicroRNAs and cancer: Current state and future perspectives in urologic oncology. Urol Oncol 28: 4-13, 2010.

9. Mu YP, Tang S, Sun WJ, Gao WM, Wang $M$ and Su XL: Association of miR-193b down-regulation and mir-196a up-regulation with clinicopathological features and prognosis in gastric Cancer. Asian Pac J Cancer Prev 15: 8893-9000, 2014.

10. Shao C, Yu Y, Yu L, Pei Y, Feng Q, Chu F, Fang Z and Zhou Y: Amplification and up-regulation of microRNA-30b in oral squamous cell cancers. Arch Oral Biol 57: 1012-1017, 2012.

11. Lu YC, Chang JT, Huang YC, Huang CC, Chen WH, Lee LY, Huang BS, Chen YJ, Li HF and Cheng AJ: Combined determination of circulating miR-196a and miR-196b levels produces high sensitivity and specificity for early detection of oral cancer. Clin Biochem 48: 115-121, 2015.

12. Qiao F, Zhang K, Gong P, Wang L, Hu J, Lu S and Fan H: Decreased miR-30b-5p expression by DNMT1 methylation regulation involved in gastric cancer metastasis. Mol Biol Rep 41: 5693-5700, 2014

13. Chen S, Li P, Yang R, Cheng R, Zhang F, Wang Y, Chen X, Sun Q, Zang W, Du Y, et al: microRNA-30b inhibits cell invasion and migration through targeting collagen triple helix repeat containing 1 in non-small cell lung cancer. Cancer Cell Int 15: $85,2015$.

14. Zhao H, Xu Z, Qin H, Gao Z and Gao L: miR-30b regulates migration and invasion of human colorectal cancer via SIX1. Biochem J 460: 117-125, 2014.

15. Zhu ED, Li N, Li BS, Li W, Zhang WJ, Mao XH, Guo G, Zou QM and Xiao B: miR-30b, down-regulated in gastric cancer, promotes apoptosis and suppresses tumor growth by targeting plasminogen activator inhibitor-1. PLoS One 9: e106049, 2014.

16. Ge YZ, Wu R, Xin H, Zhu M, Lu TZ, Liu H, Xu Z, Yu P, Zhao YC, Li MH, et al: A tumor-specific microRNA signature predicts survival in clear cell renal cell carcinoma. J Cancer Res Clin Oncol 141: 1291-1299, 2015

17. Wulfken LM, Moritz R, Ohlmann C, Holdenrieder S, Jung V, Becker F, Herrmann E, Walgenbach-Brünagel G, von Ruecker A, Müller SC and Ellinger J: MicroRNAs in renal cell carcinoma: Diagnostic implications of serum miR-1233 levels. PLoS One 6: e25787, 2011

18. Livak KJ and Schmittgen TD: Analysis of relative gene expression data using real-time quantitative PCR and the 2(-Delta Delta C(T)) Method. Methods 25: 402-408, 2001.
19. Wang ZX, Li JL, Cao JX, Liu YS, Li D, Zhang XY, Wang M, $\mathrm{Wu}$ M, Xu BL, Liu JL, et al: Cytokine-induced killer cells in the treatment of patients with renal cell carcinoma: A pooled meta-analysis. Immunotherapy 6: 787-795, 2014

20. Liu M, Tang Q, Qiu M, Lang N, Li M, Zheng Y and Bi F: miR-21 targets the tumor suppressor RhoB and regulates proliferation, invasion and apoptosis in colorectal cancer cells. FEBS Lett 585: 2998-3005, 2011

21. Zhong K, Chen K, Han L and Li B: MicroRNA-30b/c inhibits non-small cell lung cancer cell proliferation by targeting Rab18. BMC Cancer 14: 703, 2014.

22. Tian SB, Yu JC, Liu YQ, Kang WM, Ma ZQ, Ye X and Yan C: MiR-30b suppresses tumor migration and invasion by targeting EIF5A2 in gastric cancer. World J Gastroenterol 21: 9337-9347, 2015.

23. Mahdavinezhad A, Mousavi-Bahar SH, Poorolajal J, Yadegarazari R, Jafari M, Shabab $N$ and Saidijam M: Evaluation of miR-141, miR-200c, miR-30b Expression and Clinicopathological Features of Bladder Cancer. Int J Mol Cell Med 4: 32-39, 2015.

24. Lu Y, Ryan SL, Elliott DJ, Bignell GR, Futreal PA, Ellison DW, Bailey S and Clifford SC: Amplification and overexpression of Hsa-miR-30b, Hsa-miR-30d and KHDRBS3 at 8q24.22-q24.23 in medulloblastoma. PLoS One 4: e6159, 2009.

25. Heinzelmann J, Henning B, Sanjmyatav J, Posorski N, Steiner T, Wunderlich H, Gajda MR and Junker K: Specific miRNA signatures are associated with metastasis and poor prognosis in clear cell renal cell carcinoma. World J Urol 29: 367-373, 2011.

26. Gu YF, Zhang H, Su D, Mo ML, Song P, Zhang F and Zhang SC: miR-30b and miR-30c expression predicted response to tyrosine kinase inhibitors as first line treatment in non-small cell lung cancer. Chin Med J (Engl) 126: 4435-4439, 2013.

27. Liao WT, Ye YP, Zhang NJ, Li TT, Wang SY, Cui YM, Qi L, Wu P, Jiao HL, Xie YJ, et al: MicroRNA-30b functions as a tumour suppressor in human colorectal cancer by targeting KRAS, PIK3CD and BCL2. J Pathol 232: 415-427, 2014.

28. Bridge G, Monteiro R, Henderson S, Emuss V, Lagos D, Georgopoulou D, Patient R and Boshoff C: The microRNA-30 family targets DLL4 to modulate endothelial cell behavior during angiogenesis. Blood 120: 5063-5072, 2012.

29. Fuster O, Llop M, Dolz S, García P, Such E, Ibáñez M, Luna I, Gómez I, López M, Cervera J, et al: Adverse prognostic value of MYBL2 overexpression and association with microRNA-30 family in acute myeloid leukemia patients. Leuk Res 37: 1690-1696, 2013

30. Li L and Wang B: Overexpression of microRNA-30b improves adenovirus-mediated p53 cancer gene therapy for laryngeal carcinoma. Int J Mol Sci 15: 19729-19740, 2014.

31. Ichikawa T, Sato F, Terasawa K, Tsuchiya S, Toi M, Tsujimoto G and Shimizu K: Trastuzumab produces therapeutic actions by upregulating miR-26a and miR-30b in breast cancer cells. PLoS One 7: e31422, 2012. 